NASA Technical Memorandum 4430

\title{
In-Flight Flow Visualization Results From the X-29A Aircraft at High Angles of Attack
}

John H. Del Frate and John A. Saltzman

Dryden Flight Research Facility

Edwards, California

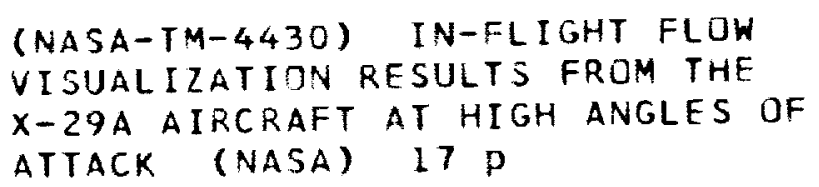

N93-13322

Unclas

$\mathrm{H1} / 02 \quad 0131939$

\section{N/S1}

National Aeronautics and

Space Administration

Office of Management

Scientific and Technical

Information Program

1992 


\title{
IN-FLIGHT FLOW VISUALIZATION RESULTS FROM THE X-29A AIRCRAFT AT HIGH ANGLES OF ATTACK
}

\author{
John H. Del Frate* \\ NASA Dryden Flight Research Facility \\ P.O. Box 273 \\ Edwards, California 93523-0273 \\ John A. Saltzman** \\ PRC Inc. \\ Edwards, California 93523-0273
}

\begin{abstract}
Flow visualization techniques were used on the $\mathrm{X}$ $29 \mathrm{~A}$ aircraft at high angles of attack to study the vortical flow off the forebody and the surface flow on the wing and tail. The forebody vortex system was studied because asymmetries in the vortex system were suspected of inducing uncommanded yawing moments at zero sideslip. Smoke enabled visualization of the vortex system and correlation of its orientation with flight yawing moment data. Good agreement was found between vortex system asymmetries and the occurrence of yawing moments. Surface flow on the forward-swept wing of the $\mathrm{X}-29 \mathrm{~A}$ was studied using tufts and flow cones. As angle of attack increased, separated flow initiated at the root and spread outboard encompassing the full wing by $30^{\circ}$ angle of attack. In general, the progression of the separated flow correlated well with subscale model lift data. Surface flow on the vertical tail was also studied using tufts and flow cones. As angle of attack increased, separated flow was observed to start at the root and spread upward. The area of separated flow on the vertical tail at angles of attack $\geq$ $20^{\circ}$ correlated well with the marked decrease in aircraft directional stability.
\end{abstract}

\section{Nomenclature}

$\begin{array}{ll}C_{L} & \text { lift coefficient } \\ C_{n_{0}} & \text { yawing moment coefficient for } 0^{\circ} \text { sideslip } \\ & \text { (positive, yaw to the right) } \\ C_{n_{\beta}} & \begin{array}{l}\text { variation of yawing moment coefficient } \\ \text { with sideslip angle, deg }\end{array}\end{array}$

\footnotetext{
Aerospace Engineer. Member, AIAA.

*Aerospace Engineer.

Copyright (C) 1992 by the American Institute of Aeronautics and Astronautics, Inc. No copyright is asserted in the United States under Title 17, U.S. Code. The U.S. Government has a royalty-free license to exercise all rights under the copyright claimed herein for Governmental purposes. All other rights are reserved by the copyright owner.
}

\author{
$C_{n_{\delta_{R}}} \quad$ variation of yawing moment coefficient \\ with rudder angle, deg \\ $C_{p} \quad$ pressure coefficient \\ FS fuselage station \\ NASA National Aeronautics and Space \\ Administration \\ $\alpha \quad$ angle of attack, deg \\ $\beta \quad$ angle of sideslip, deg (positive, nose left) \\ $\Delta C_{n_{\beta, \text { tail }}}$ variation of yawing moment coefficient with \\ sideslip angle caused by the vertical tail, \\ $C_{n_{\beta}}$ (tail-on) $-C_{n_{\beta}}$ (tail-off), deg \\ $\theta_{v} \quad$ angular location of the midplane between \\ the right and left forebody vortices $\left(0^{\circ}\right.$ \\ is top center, positive is to the right as \\ vicwed from back of aircraft, negative \\ is to the left), deg
}

\section{Introduction}

Since 1984, the X-29A (Fig. 1) has been flight tested at the National Acronautics and Space Administration (NASA) Dryden Flight Research Facility at Edwards, California. The aircraft was built by Grumman Aerospace Corporation (Bethpage, New York), and has been jointly tested by NASA, the United States Air Force, Grumman Aerospace Corp., and Honeywell Inc. (Minneapolis, Minnesota). Flight testing from May 1989 to February 1991 successfully expanded the X-29A flight envelope to include the high-angleof-attack regime. The aircraft was flown up to approximately $67^{\circ}$ angle of attack $(\alpha)$ and was found to perform well at high angles of attack. Webster and Purifoy $^{1}$ in their flight report on the high-angle-ofat tack flying qualities stated that the aircraft exhibited good longitudinal stability, control, and maneuvering characteristics below $50^{\circ}$ angle of attack. Although a mild wing rock was present at $\alpha \geq 37^{\circ}$, Webster and Purifoy reported good lateral-directional stability, control, and maneuvering characteristics for angles of attack $<45^{\circ}$. 


\section{ORIGINAL FAGE \\ BLACK AND WHITE FHOTOGRAPH}

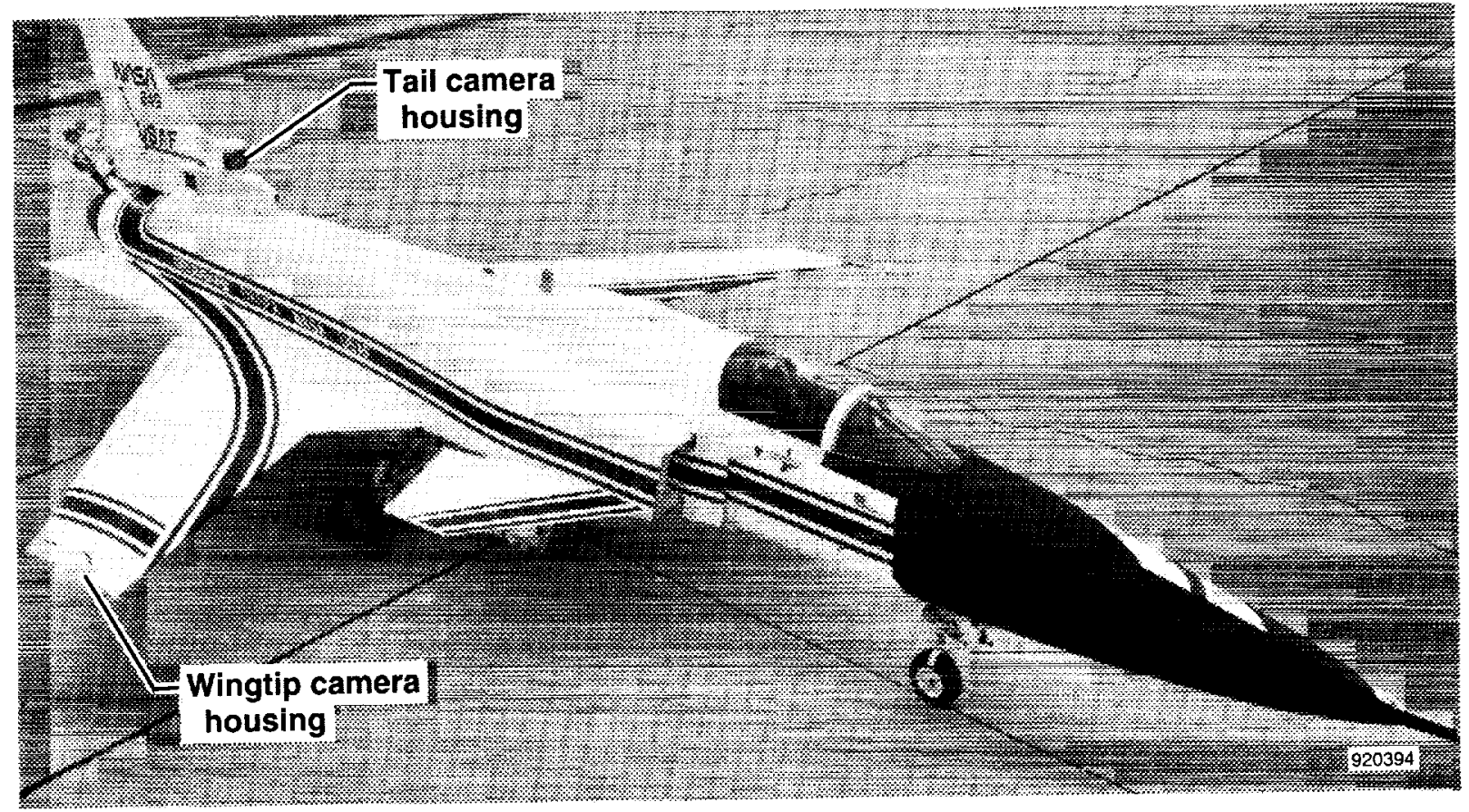

(a) Overall front right quarter view.

Fig. 1. X-29A research aircraft.

A follow-on flight test program was conducted in the summer of 1991 to perform aerodynamic investigations in three areas that were believed to affect the X-29A high-angle-of-attack characteristics. The program focused on the forebody, wing, and tail.

The forebody from an F-5A aircraft was used on the $\mathrm{X}-29 \mathrm{~A}$ to reduce developmental costs. In wind-tunnel tests before the fabrication of the aircraft, undesirable forebody vortex asymmetries were observed starting as low as $23^{\circ}$ angle of attack with the basic F-5A forebody. As a result, the forebody was modified to reduce these asymmetries. ${ }^{2,3}$ The modifications consisted of shortening the forebody and adding nose strakes. Shortening the forebody has been found to increase the onset angle of attack at which forebody vortex asymmetries form, and nose strakes have typically been employed to promote symmetrical vortex shedding. ${ }^{4}$

The forebody modifications appeared to work well, as yawing moments at zero sideslip $(\beta)$ were not observed in flight until the angle of attack reached $40^{\circ}$. Webster and Purifoy indicated that a nose-right yawing moment was encountered at $40^{\circ}$ angle of attack and remained up to $48^{\circ}$. At $\alpha>48^{\circ}$, the yawing moment reversed to the left. Webster and Purifoy as well as Klein et al. ${ }^{5}$ attributed the yawing moments to asymmetries in the forebody vortex system. To determine the effect of the forebody vortex system on the X-29A at high angles of attack, the vortices were visualized using smoke, and their positions were correlated to yawing moment data.
On a conventional aft-swept wing, as the angle of attack increases, the flow over the wing begins to separate at the wingtip and moves inboard. On a forwardswept wing, however, the flow separation begins at the wing root and moves outboard. ${ }^{2}$ This provides attached flow over the ailerons up to moderate angles of attack. In the follow-on flight program, the separation pattern was documented using surface flow visualization techniques and was correlated with overall lift on a subscale model.

Surface flow quality on the vertical tail at high angles of attack was also of interest because the tail is immersed in the low dynamic pressure wake from the wings and the fuselage. Since the vertical tail is a prime contributor to the aircraft directional stability, the flow quality on the vertical tail was correlated with subscale model directional stability as a function of angle of attack.

This paper presents descriptions of the X-29A aircraft, the flow visualization experimental setup, and the test conditions. This is followed by a discussion of the off-surface and surface flow visualization results. The surface flow visualization data on the wing and vertical tail presented in this paper range from $5^{\circ}$ to $30^{\circ}$ angles of attack. The off-surface flow visualization data of the forebody vortex system presented range from $25.5^{\circ}$ to $50.5^{\circ}$ angles of attack. 


\section{Aircraft Description}

Figure 1 shows several photos of the X-29A aircraft. The aircraft was designed as a technology demonstrator and features a forward-swept wing, close coupled canards, and relaxed static stability. ${ }^{1,2}$ A single turbofan engine powers the aircraft. The X-29A uses an F-5A forebody that was modified by shortening it 11 in. and by adding a nose strake and a flight test noseboom at the apex. ${ }^{3}$ The noseboom and strakes are indicated in Figs. 1(b) and 1(c).

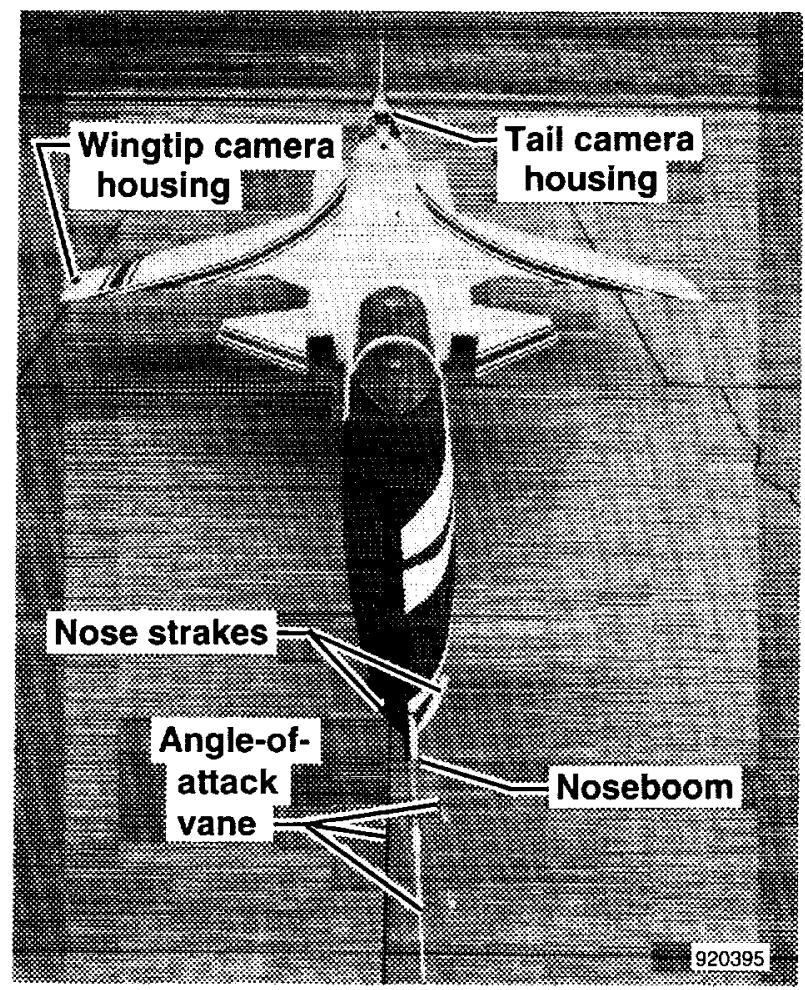

(b) Overall front view.

\section{Experimental Setup}

The forebody vortices were visualized with smoke using the same method employed on the NASA F-18 High Alpha Research Vehicle. ${ }^{6-10}$ The smoke was produced by igniting a pyrotechnic chemical composition stored in small cartridges approximately the size of soft-drink containers. Four cartridges were placed inside a housing which was located in the forebody of the X-29A. A flexible duct routed the smoke from the cartridges inside the housing to a "Y" which diverted smoke to an exhaust port on each side of the aircraft, as shown in the schematic in Fig. 2. The smoke exhaust ports are located just under the nose strakes as indicated in Fig. 1(c). The ports were 17.5-in. aft of the nose apex and had 1-in. diameters. The cartridges generated up to $30 \mathrm{sec}$ of dense white smoke. All four cartridges were required for adequate smoke density, allowing only one smoke test point per flight. Ignition of the smoke cartridges was controlled by the pilot. The smoke cartridges were found to be most effective in producing smoke at altitudes below $30,000 \mathrm{ft}$; therefore, all test points were conducted below that altitude. Figure 1(b) shows that the right side of the aircraft forebody was painted flat black. The black surface provided maximum contrast between the white smoke and the background when viewed by the wingtip cameras.

Surface flow visualization was performed on the wing upper surface and vertical tail using flow cones and tufts. $^{6-11}$ Although flow cones were preferred because of both their stability and visibility, tufts were used on some locations because they were less likely to detach in highly turbulent locations (i.e., on the wing in the canard wake at high dynamic pressure flight conditions). The tufts and flow cones were attached to the upper surface of the right wing, the right side of

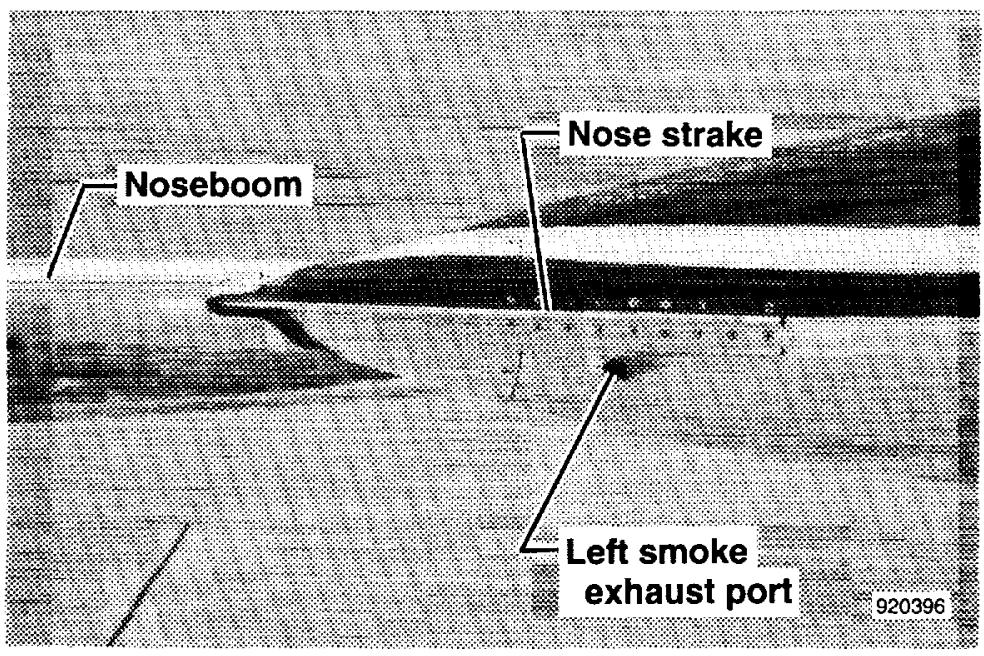

(c) Closeup of nose apex, side view.

Fig. 1. Concluded. 


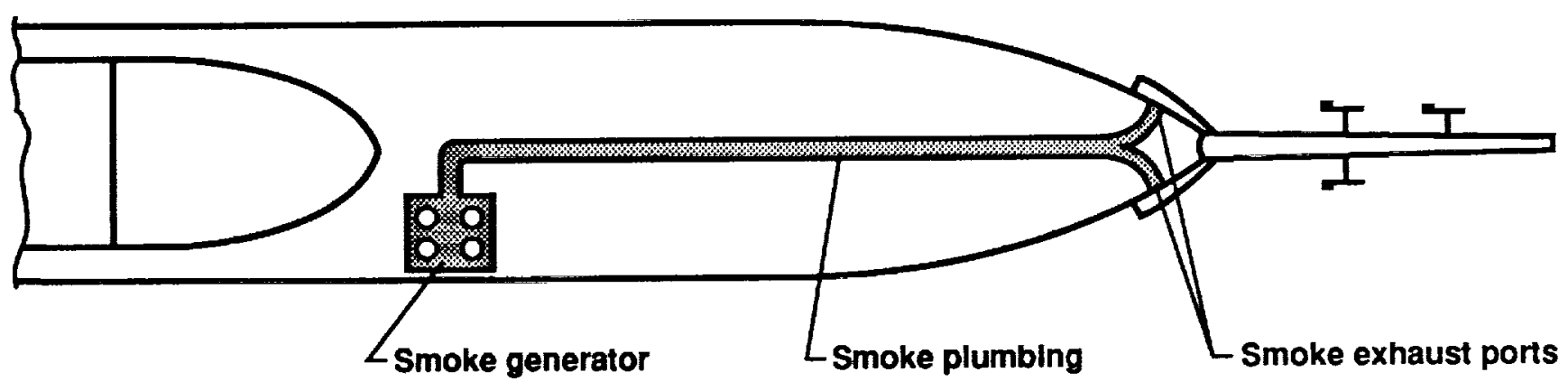

920397

Fig. 2. Top view schematic of the smoke flow visualization system (not to scale).

the vertical tail, and aft portions of the right side of the fuselage. The tufts and flow cones on the wing surface were spaced 16 in. apart in the spanwise direction and 9-12 in. apart in the chordwise direction. Vertical spacing of the tufts on the tail surface varied from 10-12 in. apart near the base to 5 in. near the top, and horizontal spacing varied from 12-16 in. near the base to 5-7 in. at the top.

The flow visualization results were recorded using two sets of cameras, which are indicated in Figs. 1(a) and $1(b)$. One set was housed at the base of the vertical tail and consisted of an 8-mm video camera-recorder (camcorder) and a $35-\mathrm{mm}$ still camera. The cameras were positioned to look either directly forward over the canopy at the smoke or to the side at the tufts and flow cones on the right wing surface. The other camera set was located at the right wingtip and consisted of a video camera and a $35-\mathrm{mm}$ still camera. This camera pair was positioned to look either at the smoke over the forward fuselage or at the tufts and flow cones on the vertical tail. The wingtip video was telemetered to the ground station, monitored by the researchers, and recorded on digital videotape. The $35-\mathrm{mm}$ cameras were controlled from the ground station. The shutter speed of the wingtip video camera was $1 / 10,000 \mathrm{sec}$ and that of the tail camcorder was $1 / 4000$ sec. The shutter speed used with the 35 -mm cameras was $1 / 1000$ sec.

Angle of attack was measured from three independent vanes mounted on the noseboom which can be seen in Fig. 1(b) (the need for three angle-of-attack vanes was a redundancy requirement for the aircraft flight control system). For high angles of attack, the vanes were calibrated using the aircraft inertial navigation system and meteorological analysis of rawinsonde balloon data. ${ }^{12,13}$ Sideslip was measured using a single vane also located on the noseboom. All flight parameters, video, and still-camera photographs were coordinated using a local timing standard.

\section{Test Conditions}

All flight test results presented were documented in 1-g flight. Three types of maneuvers were used to obtain the data: (1) stabilized at a constant angle of attack and $0^{\circ}$ sideslip, (2) wings-level sideslip at a constant angle of attack $\left(\alpha<37^{\circ}\right)$, and (3) in wing rock at constant angle of attack $\left(\alpha \geq 37^{\circ}\right)$. The wing rock at $\alpha \geq 37^{\circ}$ was uncommanded by the pilot and had a period of approximately 3 sec. Off-surface flow visualization data presented here range from $\alpha=25.5^{\circ}$ to $50.5^{\circ}$. Surface flow visualization data presented range from $\alpha=5^{\circ}$ to $30^{\circ}$. All test points were flown at altitudes between 17,000 and $30,000 \mathrm{ft}$.

\section{Results and Discussion}

\section{Off-Surface Flow Visualization}

The smoke emitted through ports below the nose strakes was entrained in the forebody vortex system and was documented by the tail and wingtip cameras. Figure 3 is a photo of the forebody vortex pair at $\alpha=$ $49.7^{\circ}$ and $\beta=-6.1^{\circ}$ as seen from the wingtip $35-\mathrm{mm}$ still camera. As angle of attack increased, the vortices seen from the wingtip camera became better defined and their distance from the top of the forebody increased. The forebody vortex pair visible in Fig. 4 was taken by the tail 35-mm still camera at $\alpha=33.2^{\circ}$ and $\beta=1^{\circ}$. The vortices appear from this view as a pair of white lobes with a dark region midplane between them. Similar tail video images were analyzed, and the pair of lobes were observed shifting to the left and right on the upper surface of the aircraft. As the lobes shifted, the dark region remained between the two lobes and shifted with them as a unit. This dark region or midplane was considered representative of the vortex system angular position. Based on the wingtip video, the image recorded by the tail cameras is believed to correspond to the longitudinal plane about halfway back on the aircraft canopy. 


\section{U. GIVAL FAGE \\ BLACK ANU WHITE PHOTCGRAFT}

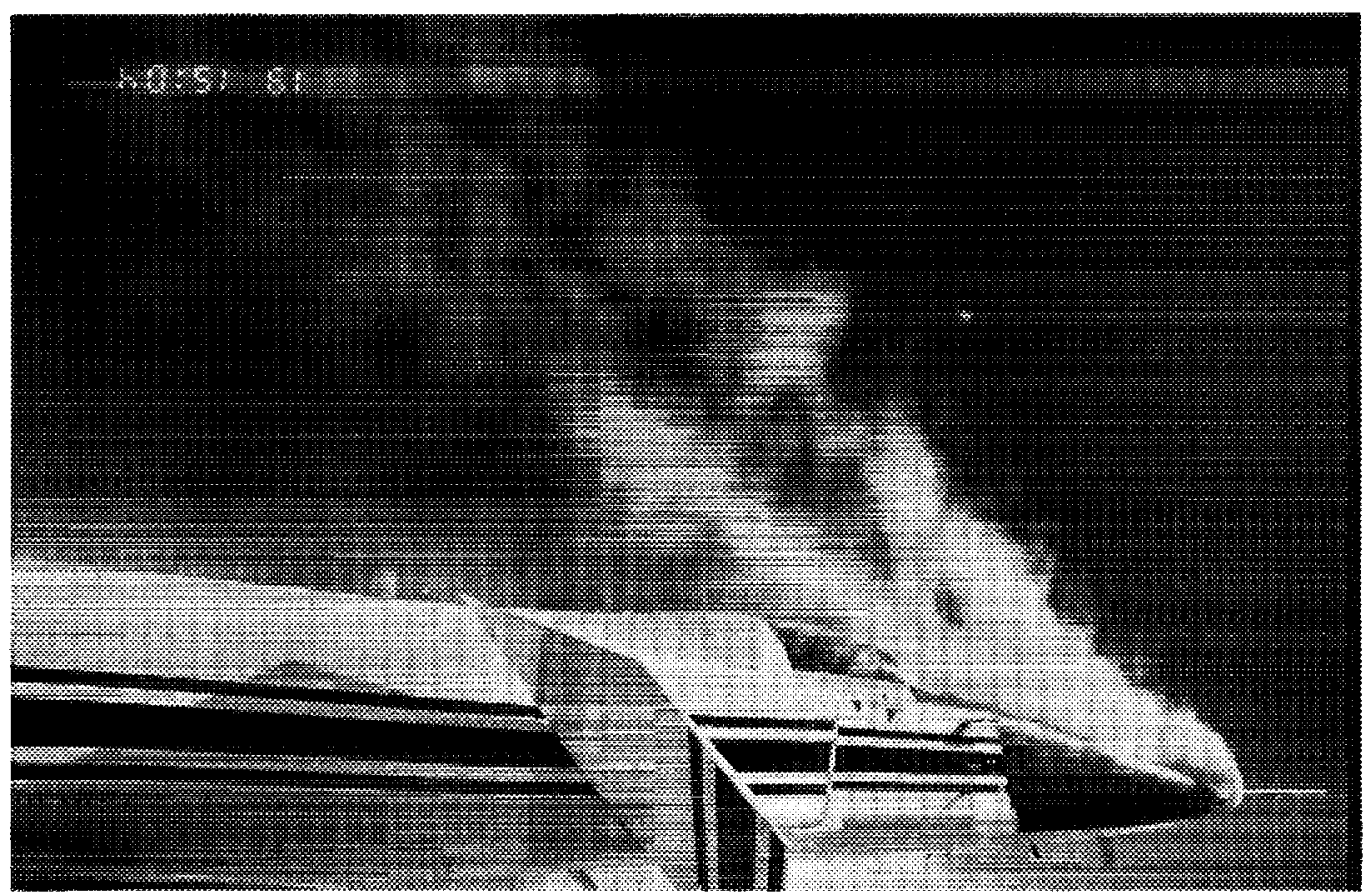

EC $91-536-17$

Fig. 3. Wingtip camera view of forebody vortices, $\alpha=49.7^{\circ}, \beta=-6.1^{\circ}$.

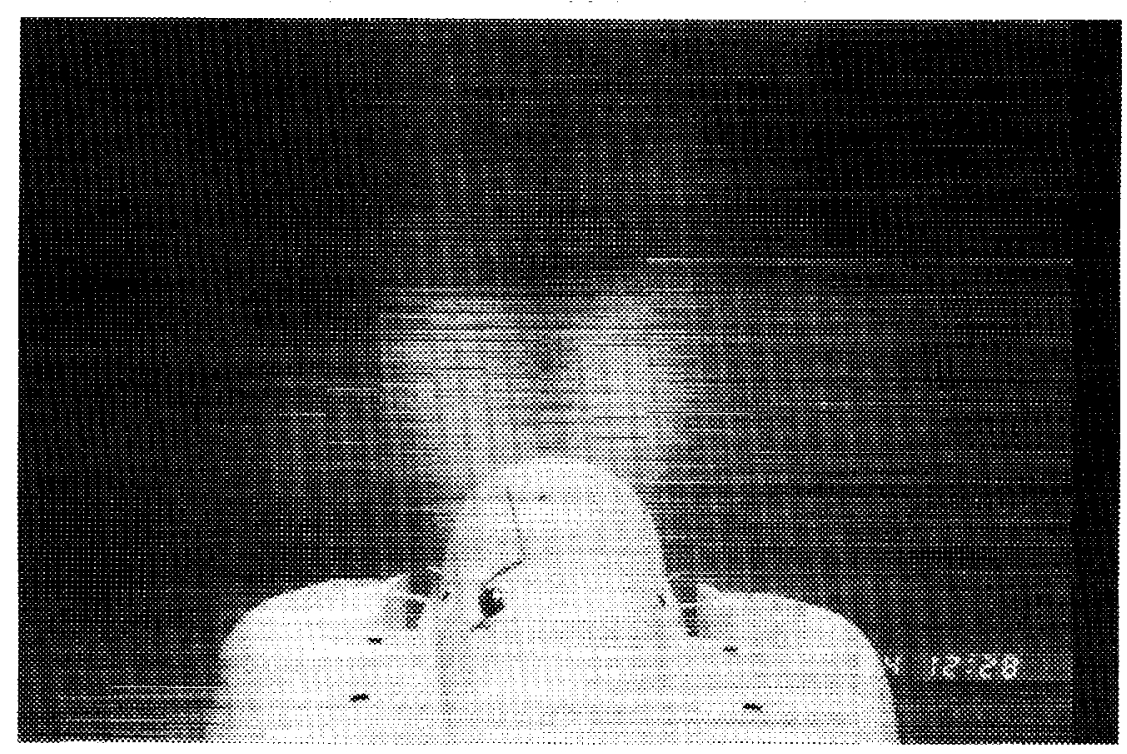

EC91-390-33

Fig. 4. Tail camera view of forebody vortices, $\alpha=33.2^{\circ}, \beta=1.0^{\circ}$.

By measuring the angular position of the forebody vortex system over a range of angle-of-attack and sideslip conditions, the existence of asymmetries was determined. Figure 5 is a sketch of the tail video camera view with the measurement reference system used. As indicated in the sketch, a line was drawn through the midplane (in this case the vortex system position is shown shifted to the left). This was accomplished for several test points at a constant angle of attack during wings-level sideslip and wing rock. The lines drawn through the midplane tended to intersect at a point just below the canopy surface as depicted in the sketch by a cross. This "center" provided a simple reference system for tracking the angular position of the vortex system. The angle between the midplane and the vertical plane was called $\theta_{v}$ and could be measured to within approximately $\pm 3^{\circ}$. As noted in Fig. $5,+\theta_{v}$ is to the right, as seen by the tail camera, and $-\theta_{v}$ is to the left. 


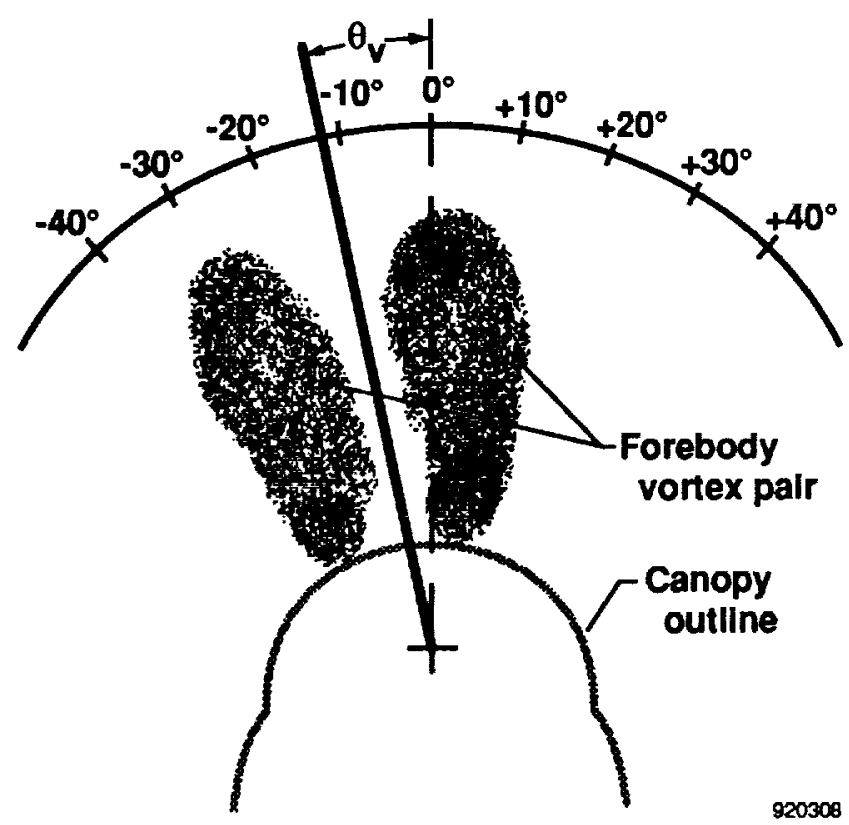

Fig. 5. Forebody vortex measurement technique.

The correlation of $\theta_{v}$ with sideslip during one typical cycle of wing rock at $\alpha=41.3^{\circ}$ is shown in Fig. 6. Each of the points shown represents the angular position of the forebody vortex system measured from individual frames of video data every $1 / 30$ sec. A straight-line approximation was faired through the complete maneuver data set. The linear approximation crossed the origin at $\beta=0^{\circ}$ indicating that at $\alpha=41.3^{\circ}$, the forebody vortex system orientation is approximately symmetrical.

The same procedure was used for test points at $\alpha=$ $25.5^{\circ}, 35.0^{\circ}, 41.3^{\circ}, 46.0^{\circ}$, and $50.5^{\circ}$. Figure 7 shows the straight-line approximations for each of the angles of attack. In general the slopes of the lines are similar; however for some angles of attack, the bias of the line at $\beta=0^{\circ}$ can be slightly positive or negative. The

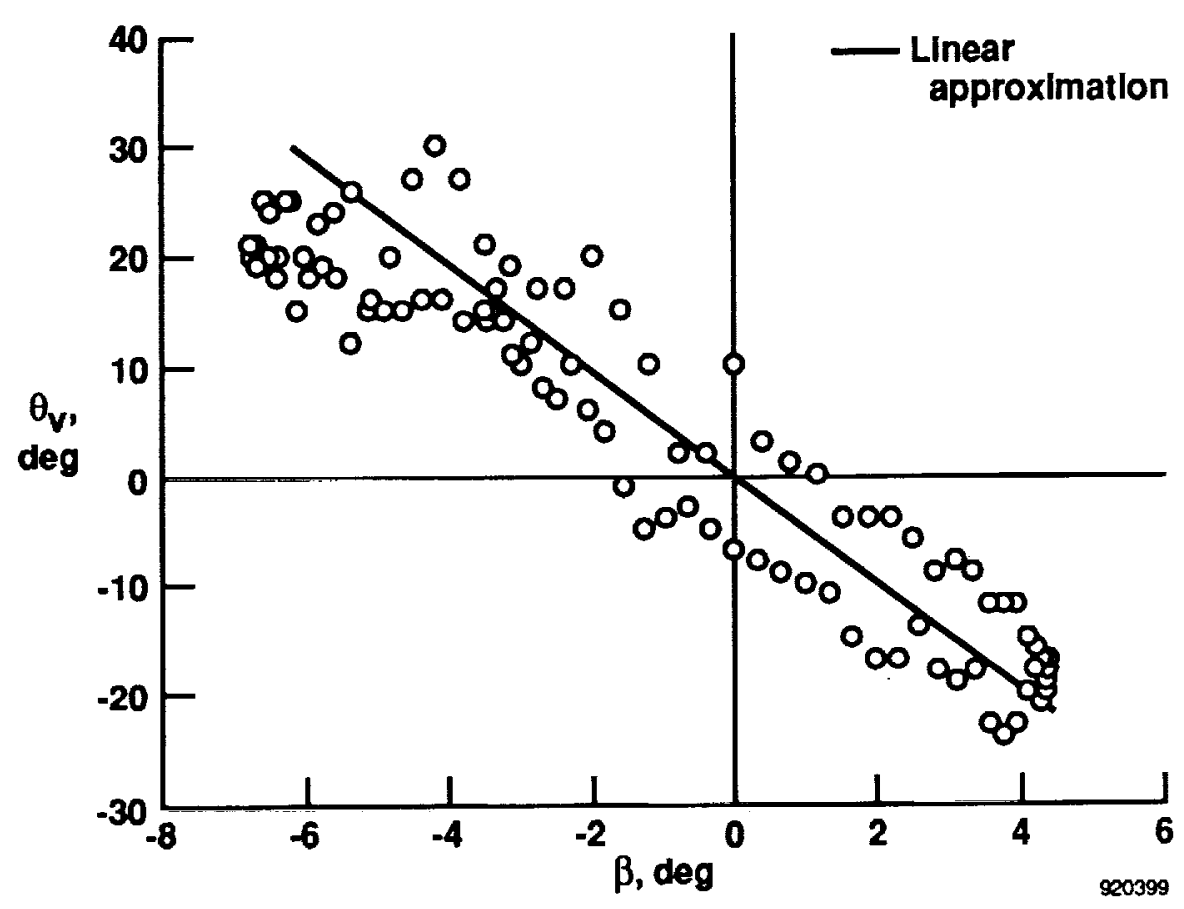

Fig. 6. Forebody vortex system position $\theta_{v}$ as a function of sideslip at $\alpha=41.3^{\circ}$. 


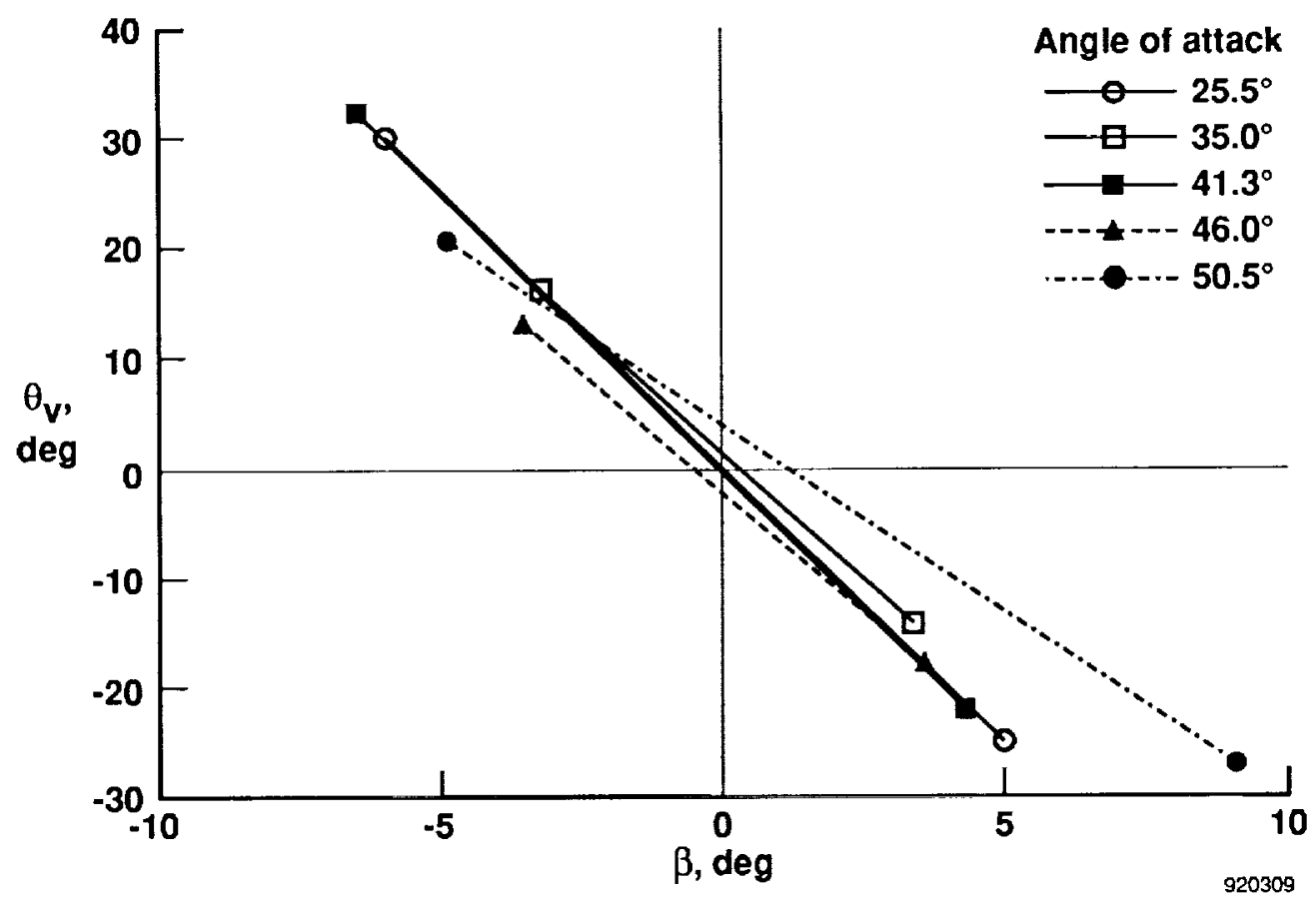

Fig. 7. Approximated forebody-vortex system position as a function of sideslip.

lines for $\alpha=25.5^{\circ}$ and $41.3^{\circ}$ cross through the origin, indicating that at $\beta=0^{\circ}$ the forebody vortices are oriented symmetrically. The lines for $\alpha=35.0^{\circ}$ and $50.5^{\circ}$ are above the origin, indicating that the forebody vortices are shifted slightly to the right. At $\alpha=$ $46.0^{\circ}$ the line lies below the origin, indicating that the forebody vortices at this condition are shifted slightly to the left.

An asymmetry in the forebody flow field (which includes the vortex system) can influence the forces acting on the forebody, as depicted in Fig. 8. The left sketch shows the approximate orientation of the forebody vortices in a positive sideslip condition. From the wingtip video it was observed that, in general, the windward vortex lies closer to the forebody surface and the leeward vortex is farther away. These findings correlate well with the forebody surface pressure results, which were also gathered during this flight program ${ }^{14}$ and are shown on the right side of Fig. 8. These results are from a ring of surface static pressure ports at fuselage station 231, just forward of the cockpit, at $\alpha=$ $44.5^{\circ}$ and $\beta=+3.3^{\circ}$ and are presented in a polar plot fashion. The view is looking forward. Note that the right side of the forebody experiences a significantly larger amount of suction than the left. This yields a net side force to the right.

Judging from the low inboard position of the windward vortex, it is likely that the vortex sheet, which feeds the vortex, separates much higher on the fuselage, and stays close to the fuselage resulting in the high suction levels. Conversely, the leeward vortex is farther outboard indicating that the vortex sheet separates lower on the fuselage and remains farther outboard resulting in lower suction levels. This agrees well with the findings in Refs. 4, 15, and 16, which are from ground facilities. It is also believed that the slight asymmetries or shifts of the forebody vortex system to the left or right at $0^{\circ}$ sideslip are indicative of an asymmetry in the pressure distribution which results in a yawing moment in the direction opposite to the shift.

Figure 9 shows the yawing moment of the $\mathrm{X}-29 \mathrm{~A}$ at $\beta=0^{\circ}\left(C_{n_{0}}\right)$ and the forebody vortex system positions, $0_{v}$, at $\beta=0^{\circ}$ as a function of angle of attack. The scale on the left corresponds to the yawing moment data with yawing moment to the right being positive. The yawing moment data set had been previously determined from parameter estimation and pilot comments in flight ${ }^{1}$ and is currently used in the flight simulator aero model. The scale on the right side of the plot corresponds to the $\theta_{v}$ data and reflects the proper yawing moment direction (for example, $-\theta_{v}$ would yield a positive yawing moment). The $\mathrm{X}-29 \mathrm{~A}$ was found to have a $C_{n_{0}}=0$ up to $\alpha=40^{\circ}$ where a right yawing moment began and continued to about $48^{\circ}$. At $\alpha>48^{\circ}$, the yawing moment reversed to the left. All vortex system data points agreed well with the yawing moment data with the exception of the data point at $\alpha=35^{\circ}$.

The generally good agreement between the uncommanded yawing moments at $\beta=0^{\circ}\left(C_{n_{0}}\right)$ and the angular position of the forebody vortex system confirms the hypothesis that the yawing moments at $\beta=0^{\circ}$ 


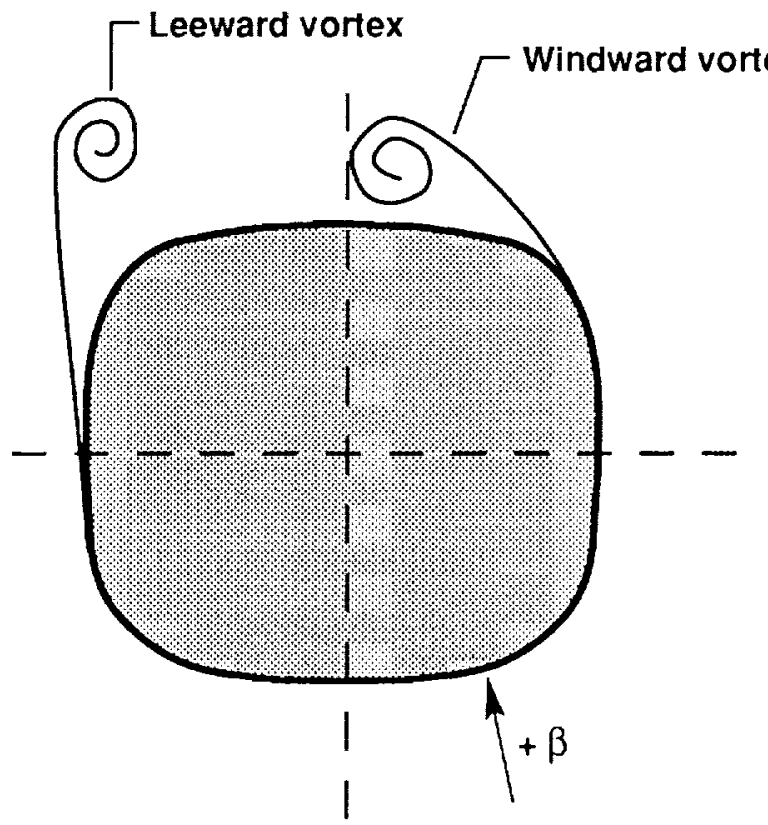

View from cockpit

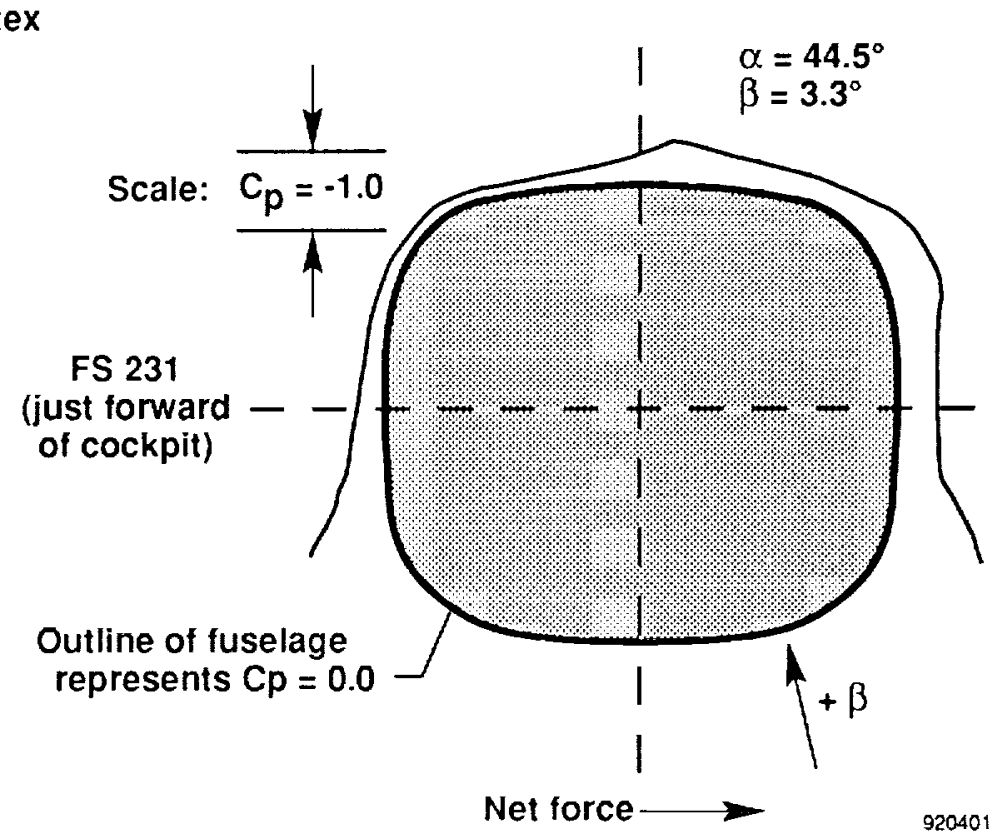

Fig. 8. Enects caused by forebody vortex system asymmetry.

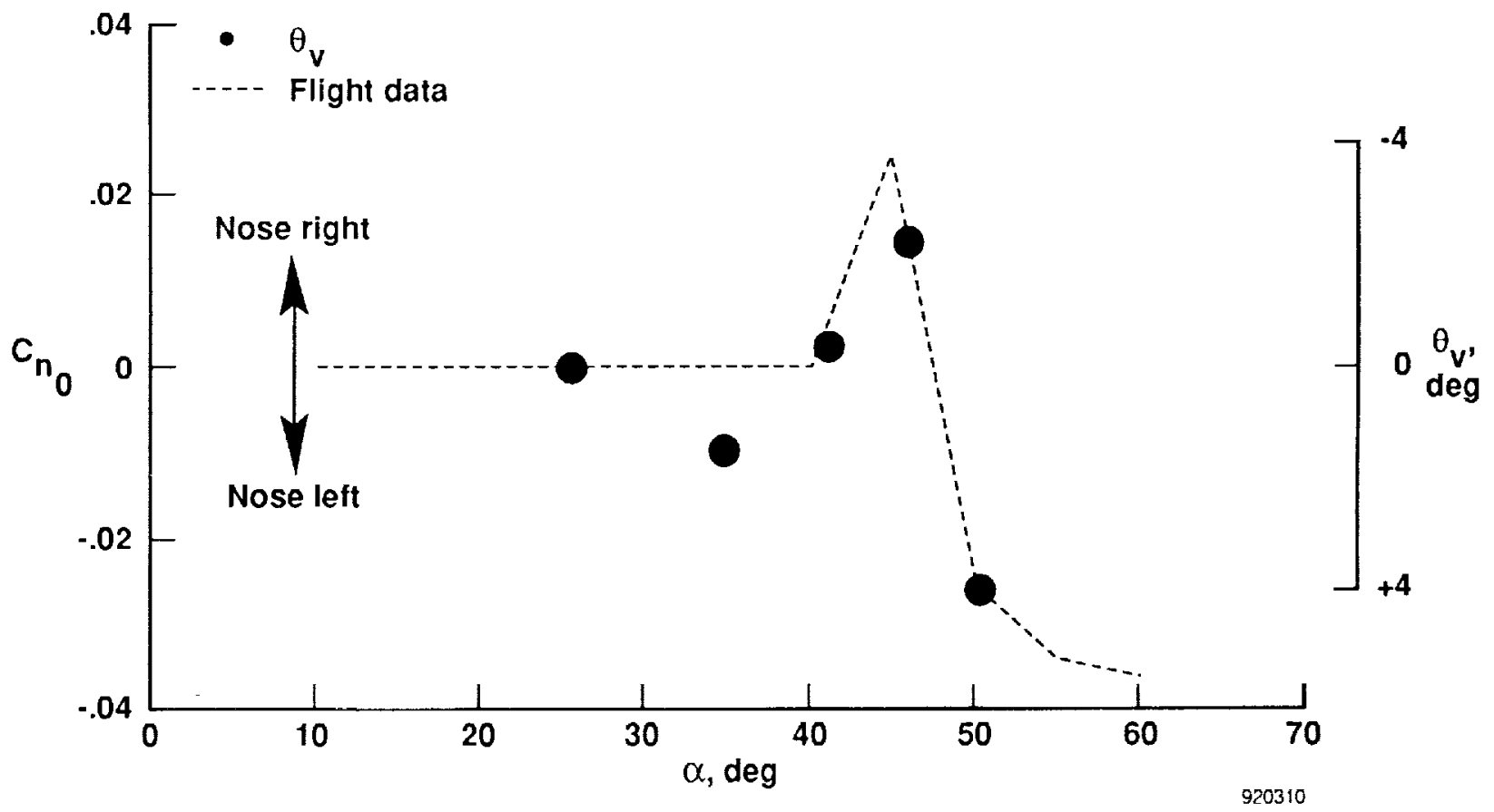

Fig. 9. Comparison of yawing moment at $0^{\circ}$ sideslip and forebody vortex system position $\theta_{v}$. 
$\left(C_{n_{0}}\right)$ at high angles of attack are related to asymmetries in vortex system. ${ }^{1,5}$ The cause of the asymmetries is not known at this time; however, because the asymmetries are repeatable they are attributed to asymmetries or irregularities on the aircraft surface.

\section{Surface Flow Visualization}

The sketches in Fig. 10 represent the three primary states of flow for the tuft and flow cones observed in this surface flow visualization investigation. The visual tuft and flow cone data were interpreted using the following chosen criteria for attached, unsteady, and separated flow. Attached flow was defined as tufts or cones in contact with the surface and showing little motion. Unsteady flow was defined as tufts or cones in contact with the surface and arcing up to approximately $\pm 35^{\circ}$. Separated flow was defined as tufts or cones on or of the surface arcing more than approximately $\pm 35^{\circ}$. This angular value was chosen because it appeared to be a natural boundary between unsteady and separated flow. The criteria were applied to video data similar in nature to the sample wing and tail photos shown in Figs. 11 and 12 respectively. Figure 11 was taken by the tail $35-\mathrm{mm}$ camera at $\alpha=11.8^{\circ}$, and Fig. 12 was taken by the wingtip $35-\mathrm{mm}$ camera at $\alpha=25.7^{\circ}$. Although similar, the video provided the researchers with more information on the changes in the surface flow with time. The tuft and cone video data were analyzed by observing the average flow behavior over a 2- to 3-sec interval of video footage.

\section{Wing Surface Flow}

The shaded area on the right wing in Fig. 13 shows the upper surface area which was visible to the tail cameras. Figure 14 shows the flow conditions of the upper surface of the right wing for several angles of attack; the conditions were determined by observing the behavior of the tufts and flow cones during stabilized 1- $g$ flight at constant angle of attack. At the upper right corner of the figure is a key to the shading used in the figure. White represents attached flow, grey represents unsteady flow, and dark grey represents separated flow.

As shown in Fig. 14, at $\alpha=5^{\circ}$ some inboard unsteady flow occurs downstream from the canards. At $\alpha=10^{\circ}$, attached and unsteady flow covers all of the wing surface and is predominantly streamwise in direction. At $\alpha=15^{\circ}$, less than half of the flow over the wing is attached or unsteady. The unsteady flow region at $\alpha=15^{\circ}$ was observed to flow spanwise from outboard to inboard, while the attached flow near the

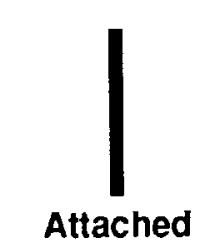

Attached

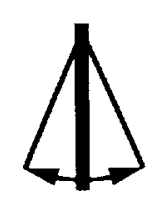

Unsteady

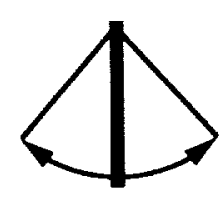

$$
\text { . }
$$

Fig. 10. Flow condition criteria for tufts and flow cones.

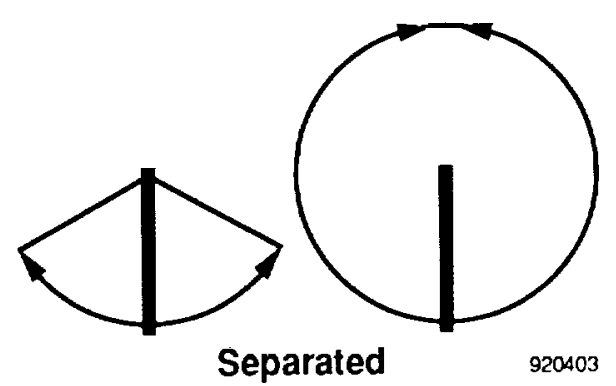

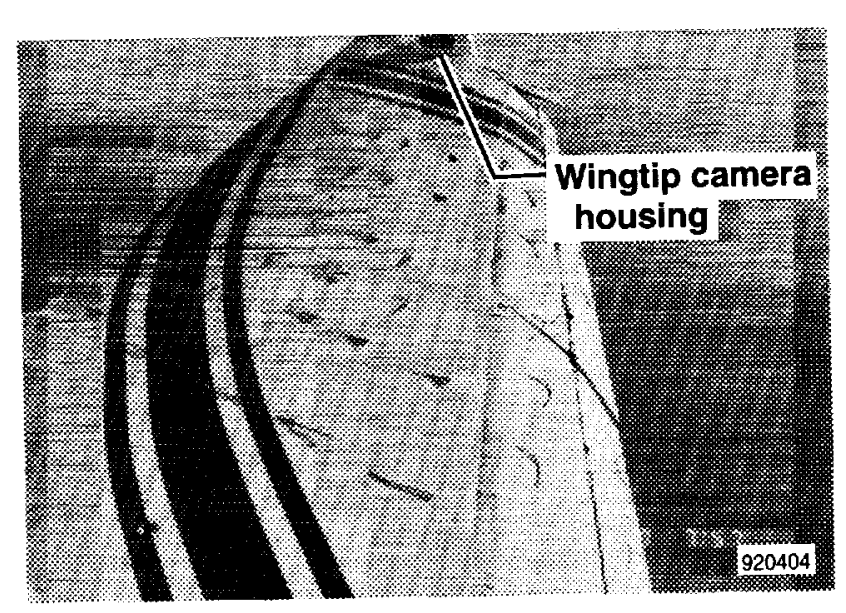

Fig. 11. Surface flow visualization photograph of the upper surface of the right wing taken from the tail camera at $\alpha=11.8^{\circ}$. wingtip flowed streamwise. Between $\alpha=15^{\circ}$ and $25^{\circ}$, the amount of attached and unsteady flow on the outboard region of the wing continues to decrease, but the decrease is more gradual than at lower angles of attack. In addition, in the angle of attack range between $15^{\circ}$ and $25^{\circ}$, as the angle increases, the orientation of the flow over the outboard section of the wing becomes increasingly spanwise. At $\alpha=25^{\circ}$ and above, some reversed separated flow was noticed around the trailing edge and at 70 percent of the wing semispan. At $\alpha=$ $30^{\circ}$, the complete wing upper surface is separated.

The general trend observed in the tuft and flow-cone movement was that the more disturbed flow begins at the wing root. With increasing angle of attack, the now disturbance increases in intensity (from attached 


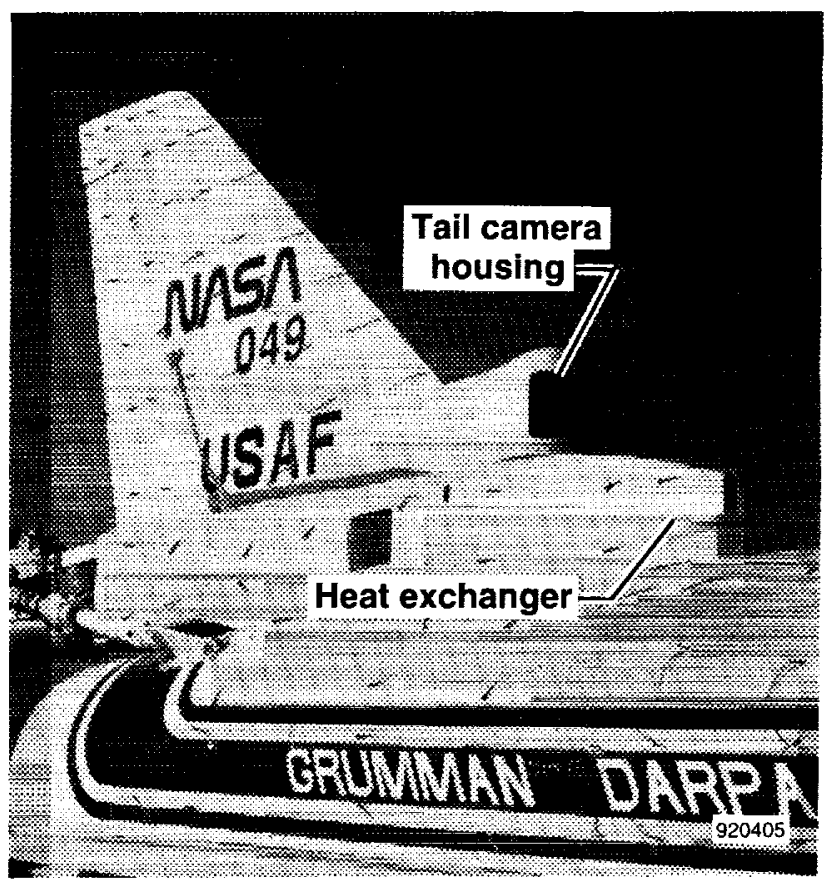

Fig. 12. Surface flow visualization photograph of the right side of the vertical tail taken by the wingtip camera at $\alpha=25.7^{\circ}$.

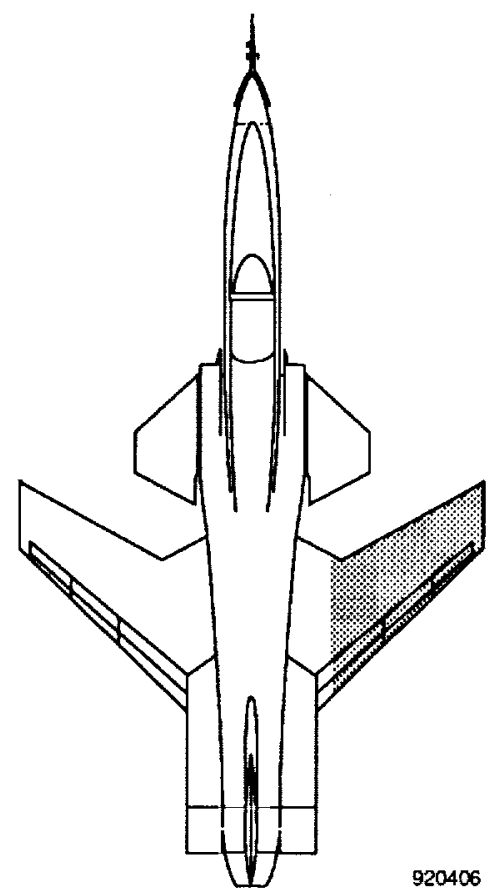

Fig. 13. Tail camera view of the right wing.

to unsteady to separated) and spreads outboard as expected. ${ }^{2}$ By $\alpha=30^{\circ}$, flow on the upper surface of the wing is completely separated.

Figure 15 is a plot of lift coefficient $C_{L}$ (determined from unpublished wind-tunnel data*) as a function of angle of attack for the X-29A configuration. The lift curve slope is steepest between $\alpha=0^{\circ}$ and $10^{\circ}$, which is primarily a result of increasing wing camber (the flight control system schedules the camber to stop increasing at $\alpha=10^{\circ}$ ). The surface flow visualization results, however, showed an absence of separated flow at these angles of attack which, we believe, also contributes favorably to the lift curve slope. At $\alpha=10^{\circ}$, a large reduction in the lift curve slope occurs. This reduction is partly caused by the camber scheduling; however, the large increase in separated flow over the wing between $\alpha=10^{\circ}$ and $15^{\circ}$ is also believed to contribute to the reduction. At $\alpha=20^{\circ}, 25^{\circ}$, and $30^{\circ}$ there are subsequent increases in separated flow; this trend correlates well with the gradual reduction in the lift curve slope.

\section{Tail Surface Flow}

The sketches in Fig. 16 show the flow conditions on the right surface of the vertical tail of the X-29A for several angles of attack. These conditions were determined by observing the behavior of the tufts on video recorded by the right wingtip camera during stabilized 1-g flight at a constant angle of attack. The same shading codes are used here as were used in the wing results.

As shown in Fig. 16 , from $\alpha=5^{\circ}$ to $15^{\circ}$, attached and unsteady flow covers all of the vertical tail surface with the exception of separated flow in the region directly downstream of the tail camera fairing, which is also the likely cause of the separated flow. In the attached and unsteady region, the surface flow is predominantly streamwise in direction. At $\alpha=20^{\circ}$, separated flow covers the entire heat exchanger, located under the vertical tail, and merges with the separated flow downstream of the camera fairing. Unsteady and attached flow still covers most of the tail surface. By $\alpha=25^{\circ}$, the separated flow region has spread upward considerably leaving only the tip covered in unsteady flow with a slight spanwise orientation. There is no evidence of attached flow at $\alpha=25^{\circ}$, and at $\alpha>30^{\circ}$ the complete vertical tail surface is covered with separated flow.

The general trend observed in the tufts was that the more disturbed flow begins at the base of the vertical tail, as expected because of the wake of the camera fairing, and the proximity of the fuselage and wing wake. With increasing angle of attack, the flow disturbance caused by the fuselage and wing wake rises up the vertical tail. By $\alpha=30^{\circ}$, flow on the vertical tail surface appeared completely separated.

\footnotetext{
"Krumenacker, J., "Revised X-29A Iligh Angle of Attack, Flexible Aerodynamic Math Model (AERO9B); Equations, Computer Subroutines, and Data Tables," Grumman Aircraft Systems Division (GASD) Memo No. 712/ENG-M-88054, Nov. 1988 (unpublished).
} 


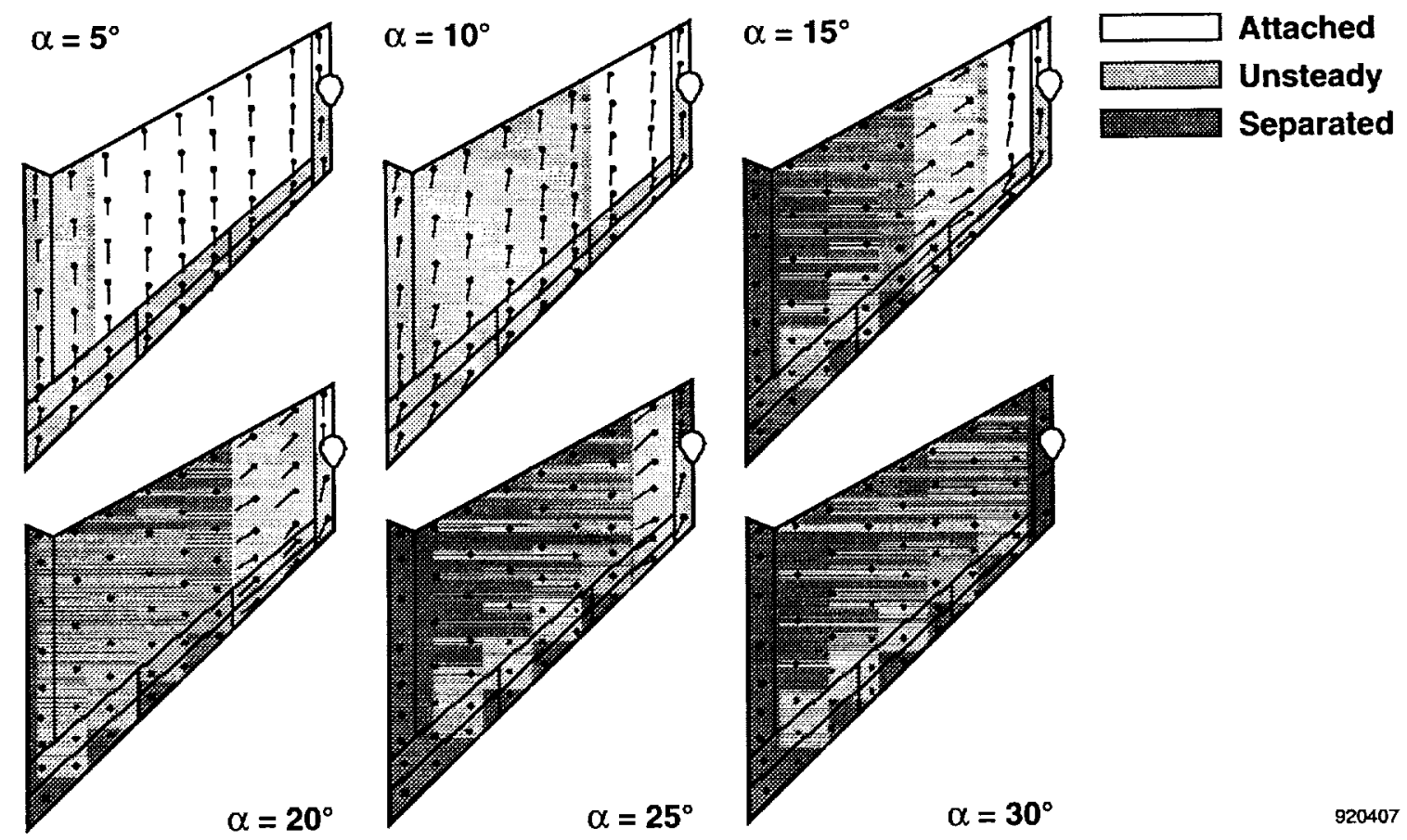

Fig. 14. Flow conditions of the upper surface of the right wing for various angles of attack.

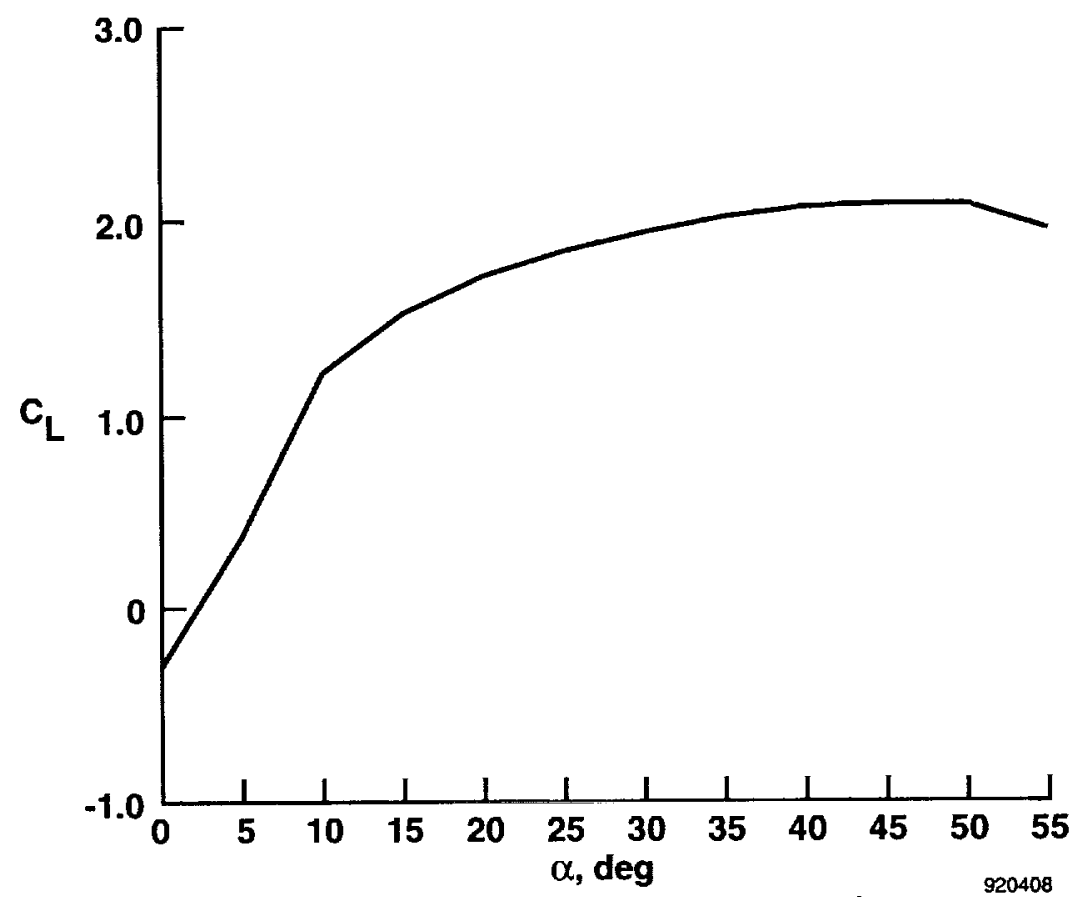

Fig. 15. Wind-tunnel-derived lift coefficient as a function of angle of attack.

Figure 17 is a plot which shows the directional stability $\left(\Delta C_{n_{\beta, \text { tail }}}\right)$ as a function of angle of attack caused by the tail. The directional stability was computed by subtracting the vertical tail-off $C_{n_{\beta}}$ from the tail-on $C_{n_{\beta}}$ (unpublished wind-tunnel data). On the average, the stability curve has a positive slope up to $\alpha \approx 20^{\circ}$, correlating well with the surface flow visualization data which showed little or no separated flow on the upper vertical tail surface at these conditions. Between $\alpha=20^{\circ}$ and $35^{\circ}$, the $\Delta C_{n_{\beta, \text { tail }}}$ value decreases considerably. This sharp decrease correlates well with the large increases in separated flow on the tail for the corresponding angles of attack. Recall that by $\alpha=30^{\circ}$ separated flow covered the entire vertical tail surface. 

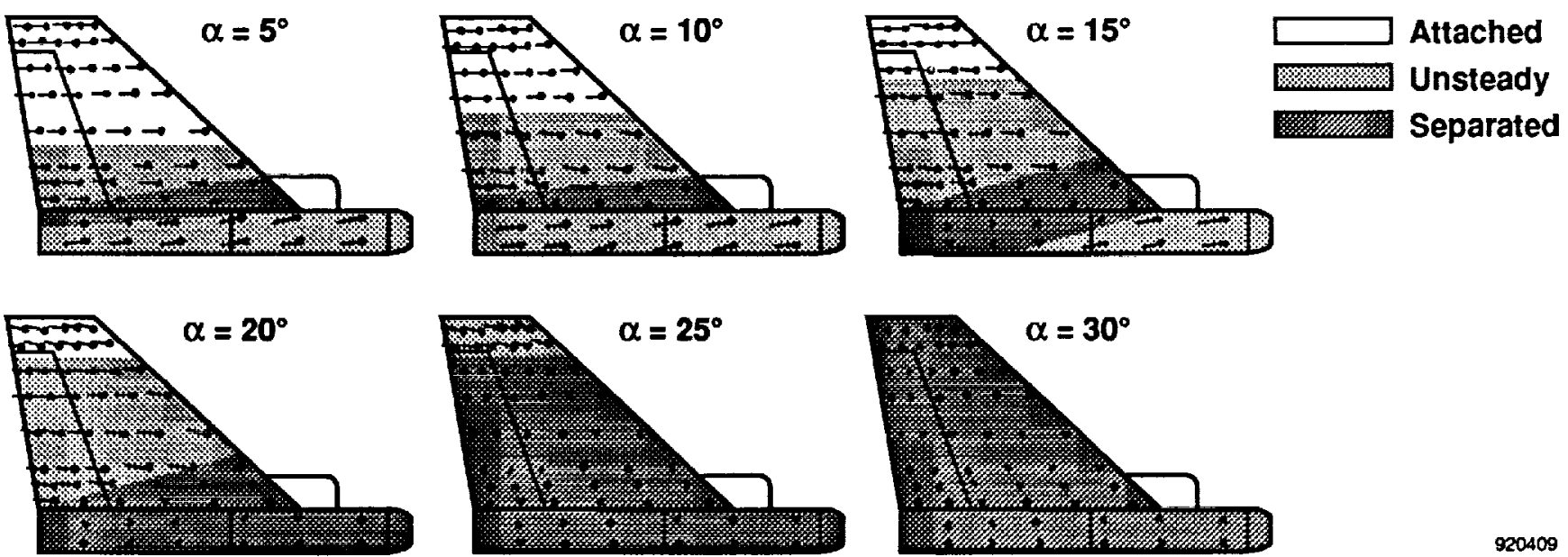

Fig. 16. Flow conditions of the vertical tail (right side) at various angles of attack.

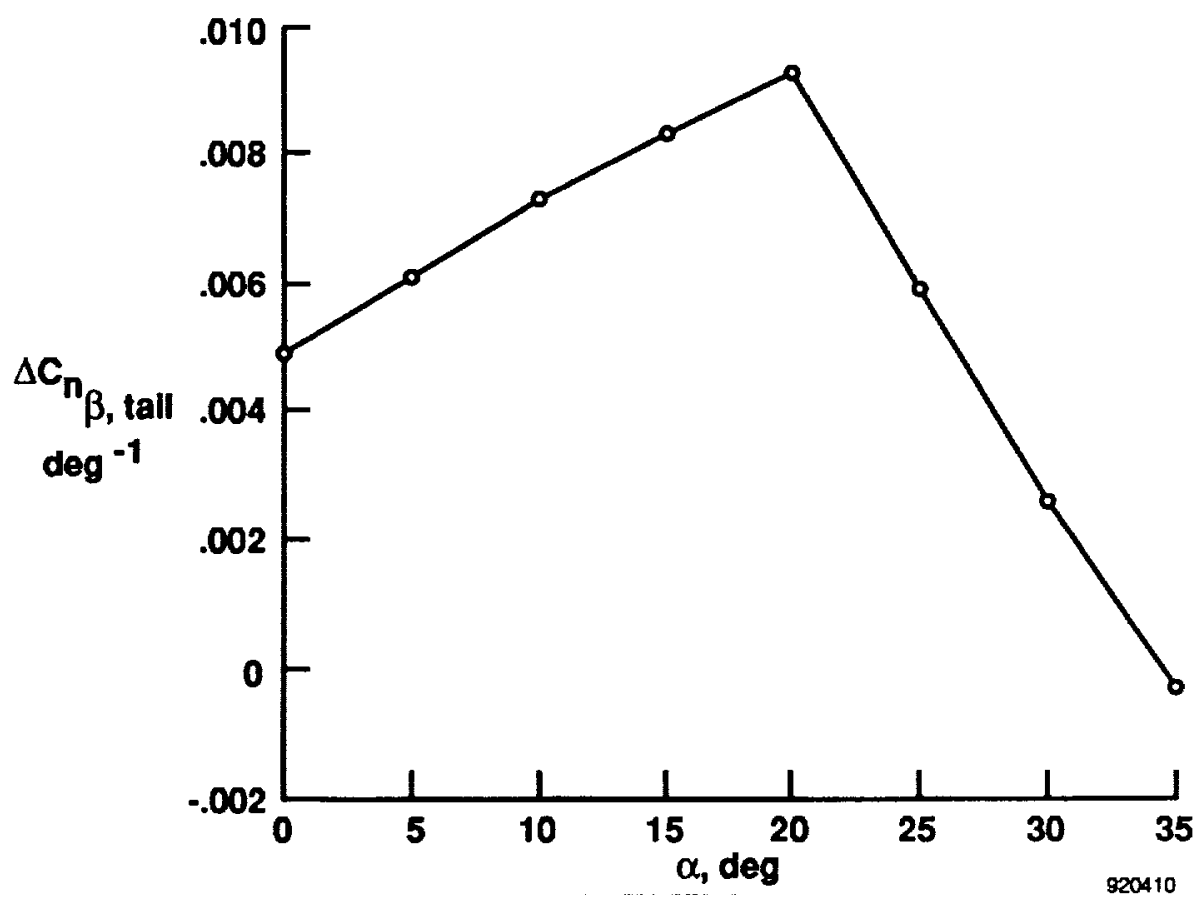

Fig. 17. Directional stability caused by the vertical tail as a function of angle of attack.

As might be expected, rudder efficiency also suffers at the higher angles of attack. The plot in Fig. 18 is wind-tunnel data of the yawing moment caused by rudder deflection $\left(C_{n_{\delta_{R}}}\right)$ as a function of angle of attack. ${ }^{1}$ A significant decrease in rudder efficiency starts at $\alpha=15^{\circ}$ with a sharp increase in the rate of decline starting at $\alpha \approx 24^{\circ}$. The sharp decreases in rudder control also correlated well with the large increases in separated flow observed on the vertical tail surface as angle of attack increased. 


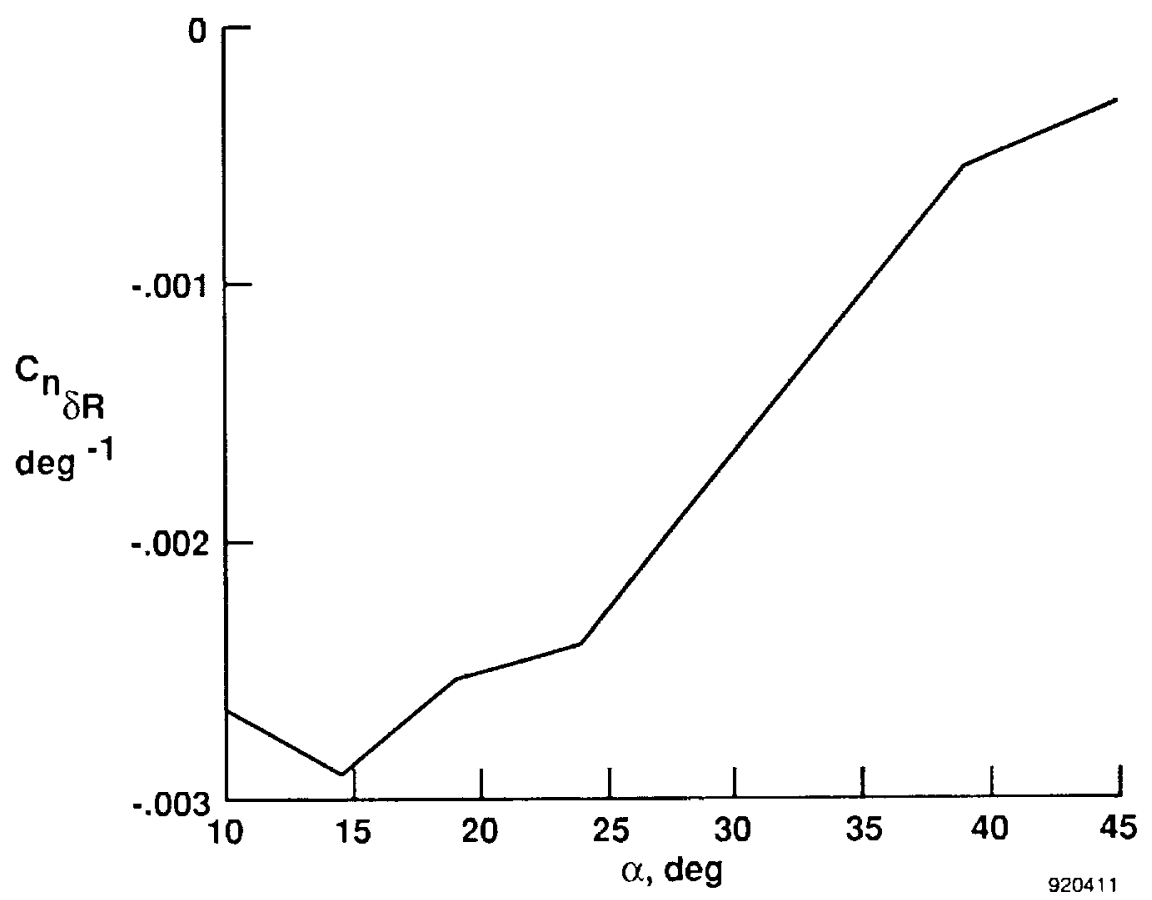

Fig. 18. Yawing moment caused by rudder deflection as a function of angle of attack.

\section{Concluding Remarks}

Surface and off-surface flow visualization methods were successfully applied to the $\mathrm{X}-29 \mathrm{~A}$ at high angles of attack. The off-surface flow visualization method consisted of entraining smoke in the forebody vortex system. The surface flow methods consisted of attaching tufts and flow cones to the vertical tail and the: upper surface of the right wing.

The relationship between the angular position of the forebody vortex system and the sideslip angle was determined for several angles of attack. For $0^{\circ}$ sideslip at certain angles of attack, the vortex system was oriented slightly to the left or to the right. These orientations correlated well with $0^{\circ}$ sideslip yawing moment $\left(C_{t_{0}}\right)$ data previously determined for this aircraft.

With increasing angle of attack, the separated flow initiated at the wing root and spread outboard covering the entire wing by $30^{\circ}$ angle of attack. The large reduction in the lift curve slope at angles of attack > $10^{\circ}$ correlated well with the increase in separated flow on the wing upper surface.

Flow separation on the vertical tail at angles of attack $\geq 20^{\circ}$ correlated well with the large decrease in directional stability due to the tail for corresponding angles of attack. This is likely the result of the tail being immersed in the low energy wake of the aircraft fuselage and wings.

\section{References}

${ }^{1}$ Webster, Fredrick R. and Dana Purifoy, X-29 High Angle of Altack Flying Qualities, AFFTC-TR-91-15, July 1991.

${ }^{2}$ Moore, M. and D. Frei, "X-29 Forward Swept Wing Aerodynamic Overview," $M \Lambda \Lambda$-83-1834, July 1983.

${ }^{3}$ Frei, Douglas, Melvin Garelick, Ronald Hendrickson, and Glenn Spacht, Forward Swept Wing Study, Technical Report AFFDL-TR-79-3151, Jan. 1980.

${ }^{4}$ Skow, A. M. and G. E. Erickson, "Modern Fighter Aircraft Design for High Angle-of-Attack Maneuvering," in High Angle-of-Altack Acrodynamics, AGARDL.S-121, Dec. 1982 , pp. 1.1 to 4-59.

${ }^{5}$ Klein, Vladislav, Brent R. Cobleigh, and Keith D. Noderer, Lalcral Acrodynamic Parameters of the $X$ 29A Aircraft Estimated From Data al Moderate to High Angles of Allack, NASA TM-104155, 1991.

${ }^{6}$ Fisher, David F. and Robert R. Meyer, Jr., Flow Visualization Techniques for Flight Rescarch, NASA TM-100455, 1988.

${ }^{7}$ Richwine, David M., Robert E. Curry, and Gene V. Tracy, A Smoke Generator System for Acrodynamic Flight Rescarch, NASA TM-1137, 1989.

${ }^{8}$ Fisher, David F., John II. Del Frate, and David M. Richwine, In-Flight Flow Visualizalion Characlerislics of the NASA F-18 High Alpha Rescarch Vehicle at High Angles of Altack, NASA TWM-4193, 1990. 
${ }^{9}$ Del Frate, John H., David F. Fisher, and Fanny A. Zuniga, In-Flight Flow Visualization with Pressure Measurements at Low Speeds on the NASA F-18 High Alpha Research Vehicle, NASA TM-101726, 1990.

${ }^{10}$ Yang, Wen-Jei (ed.), Handbook of Flow Visualization, Hemisphere Publishing Corp., 1989.

${ }^{11}$ Crowder, J.P. and P.E. Robertson, "Flow Cones for Airplane Flight Test Flow Visualization," in Flow Visualization III, W.J. Yang, ed., Hemisphere Publishing Corp., 1985, pp. 60-64.

${ }^{12}$ Pellicano, Paul, Joseph Krumenacker, and David Vanhoy, "X-29 High Angle-of-Attack Flight Test Procedures, Results, and Lessons Learned," presented at the 21st Annual Symposium of the Society of Flight Test Engineers, Garden Grove, California, Aug. 1990.
${ }^{13}$ Rajczewski, David M., Capt., "X-29 High Angleof-Attack Flight Test: Air Data Comparisons of an Inertial Navigation System and Noseboom Probe," presented at the 21st Annual Symposium of the Society of Flight Test Engineers, Garden Grove, California, Aug. 1990.

${ }^{14}$ Fisher, David F., D.M. Richwine, and S.F. Landers, "Correlation of Forebody Pressures and Aircraft Yawing Moments on the X-29A Aircraft at High Angles of Attack," AIAA-92-4105, Aug. 1992.

${ }^{15}$ Grafton, S.B., J.R. Chambers, and Paul L. Coe, $\mathrm{J}_{r}$, Wind-Tunnel Free-Flight Investigation of a Model of a Spin-Resistant Fighter Configuration, NASA TND-7716, 1974.

${ }^{16}$ Keener, Earl R., Flow-Separation Patterns on Symmetric Forebodies, NASA TM-86016, 1986. 




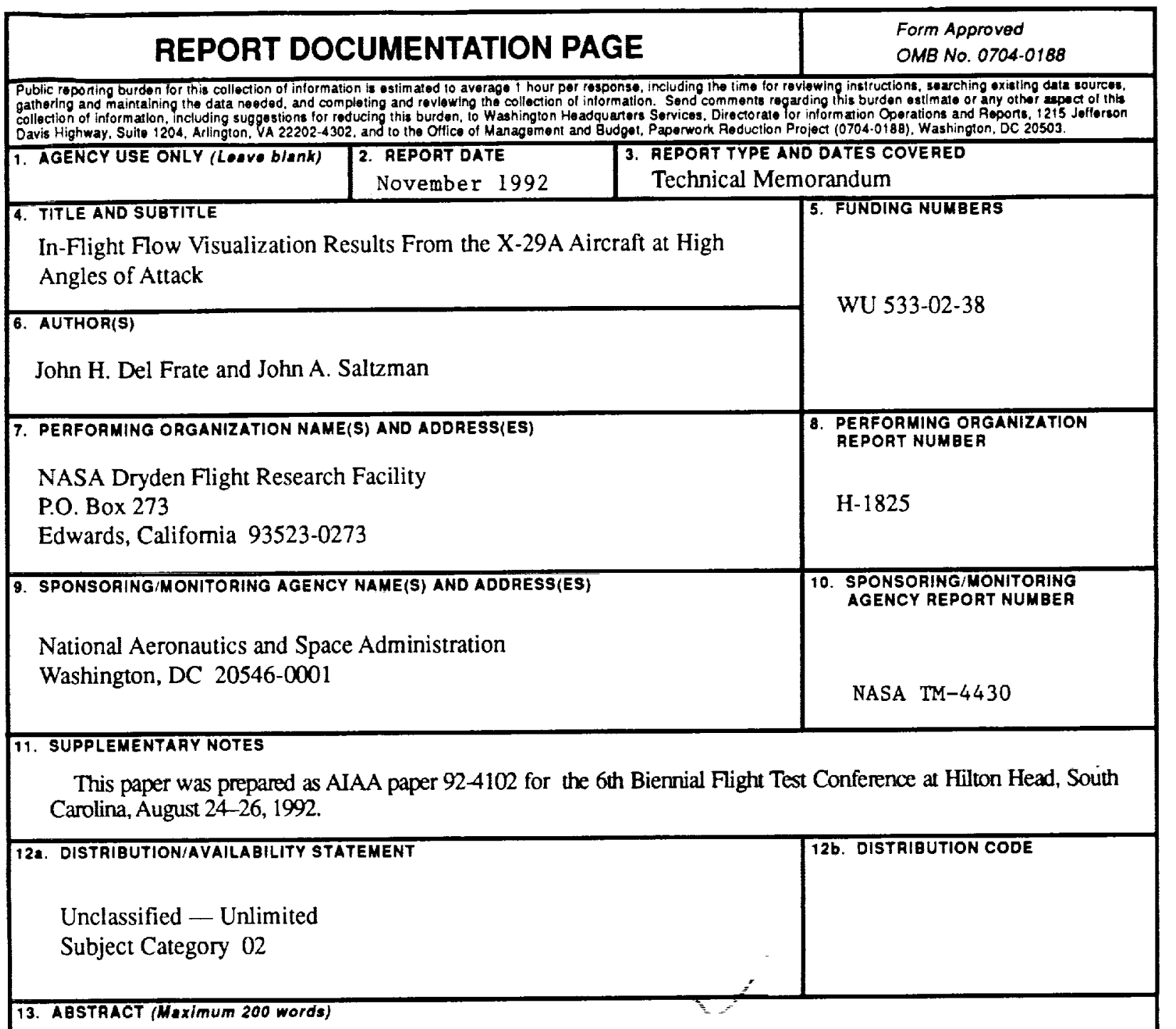

Flow visualization techniques were used on the X-29A aircraft at high angles of attack to study the vortical flow off the forebody and the surface flow on the wing and tail. The forebody vortex system was studied because asymmetries in the vortex system were suspected of inducing uncommanded yawing moments at zero sideslip. Smoke enabled visualization of the vortex system and correlation of its orientation with flight yawing moment data. Good agreement was found between vortex system asymmetries and the occurrence of yawing moments. Surface flow on the forward-swept wing of the X-29A was studied using tufts and flow cones. As angle of attack increased, separated flow initiated at the root and spread outboard encompassing the full wing by $30^{\circ}$ angle of attack. In general, the progression of the separated flow correlated well with subscale model lift data. Surface flow on the vertical tail was also studied using tufts and flow cones. As angle of attack increased, separated flow initiated at the root and spread upward. The area of separated flow on the vertical tail at angles of attack $>20^{\circ}$ correlated well with the marked decrease in aircraft directional stability.

\begin{tabular}{|c|c|c|c|}
\hline \multirow{2}{*}{\multicolumn{3}{|c|}{$\begin{array}{l}\text { 14. SUBJECT TERMS } \\
\text { In-flight flow visualization; X-29A aircraft; High angles of attack; Separated flow; } \\
\text { Vortical flow }\end{array}$}} & $\begin{array}{l}\text { 15. NUMBEA OF PAGES } \\
16\end{array}$ \\
\hline & & & $\begin{array}{l}\text { 16. PAICE CODE } \\
\mathrm{A} 03\end{array}$ \\
\hline $\begin{array}{l}\text { 17. SECUAITY CLASSIFICATION } \\
\text { OF REPORT } \\
\text { Unclassified }\end{array}$ & $\begin{array}{l}\text { 18. SECUAITY CLASSIFICATION } \\
\text { OF THIS PAGE } \\
\text { Unclassified }\end{array}$ & $\begin{array}{l}\text { 19. SECUAITY CLASSIFICATION } \\
\text { OF ABSTRACT } \\
\text { Unclassified }\end{array}$ & $\begin{array}{l}\text { 20. LIMITATION OF ABSTRACT } \\
\text { Unlimited }\end{array}$ \\
\hline
\end{tabular}

